\title{
Large-scale integration of cancer microarray data identifies a robust common cancer signature Lei $\mathrm{Xu}^{* 1}$, Donald Geman ${ }^{1,2}$ and Raimond L Winslow ${ }^{1}$
}

\author{
Address: ${ }^{1}$ The Institute for Computational Medicine and Center for Cardiovascular Bioinformatics and Modeling, Johns Hopkins University, \\ Baltimore, MD 21218, USA and 2Department of Applied Mathematics and Statistics and Center for Imaging Sciences, Johns Hopkins University, \\ Baltimore, MD 21218, USA \\ Email: Lei Xu* - leixu@jhu.edu; Donald Geman - geman@jhu.edu; Raimond LWinslow - rwinslow@jhu.edu \\ * Corresponding author
}

Published: 30 July 2007

BMC Bioinformatics 2007, 8:275 doi:10.1 186/147|-2/05-8-275
Received: 15 February 2007

Accepted: 30 July 2007

This article is available from: http://www.biomedcentral.com/147/-2/05/8/275

(c) 2007 Xu et al; licensee BioMed Central Ltd.

This is an Open Access article distributed under the terms of the Creative Commons Attribution License (http://creativecommons.org/licenses/by/2.0), which permits unrestricted use, distribution, and reproduction in any medium, provided the original work is properly cited.

\begin{abstract}
Background: There is a continuing need to develop molecular diagnostic tools which complement histopathologic examination to increase the accuracy of cancer diagnosis. DNA microarrays provide a means for measuring gene expression signatures which can then be used as components of genomic-based diagnostic tests to determine the presence of cancer.

Results: In this study, we collect and integrate 1500 microarray gene expression profiles from 26 published cancer data sets across 21 major human cancer types. We then apply a statistical method, referred to as the Top-Scoring Pair of Groups (TSPG) classifier, and a repeated random sampling strategy to the integrated training data sets and identify a common cancer signature consisting of 46 genes. These 46 genes are naturally divided into two distinct groups; those in one group are typically expressed less than those in the other group for cancer tissues. Given a new expression profile, the classifier discriminates cancer from normal tissues by ranking the expression values of the $\mathbf{4 6}$ genes in the cancer signature and comparing the average ranks of the two groups. This signature is then validated by applying this decision rule to independent test data.

Conclusion: By combining the TSPG method and repeated random sampling, a robust common cancer signature has been identified from large-scale microarray data integration. Upon further validation, this signature may be useful as a robust and objective diagnostic test for cancer.
\end{abstract}

\section{Background}

During the past century, the presence of cancer in tissues has been diagnosed on the basis of histopathology [1]. The major limitation of this approach is that it cannot achieve high accuracy of prediction in clinical practice. Therefore, there has been a persistent need to identify robust cancer signatures which could complement conventional histopathologic evaluation to increase the accuracy of cancer detection [2]. More recently, DNA microarrays have been developed as a means to simultaneously measure the transcript abundance (gene expres- sion level) of mRNA for thousands of genes. This technology provides a potentially powerful tool for identifying molecular signatures capable of accurately detecting the presence of cancer.

Many studies have used DNA microarrays to identify cancer type-specific gene expression signatures which can discriminate certain types of cancer from normal tissues [315]. The diversity of these signatures makes it difficult to distinguish the genes that play a crucial role in oncogenic processes from those that are spuriously differentially 
expressed and therefore irrelevant to the oncogenic processes. Since all cancer cells share two common characteristics, uncontrollable growth and local tissue invasion or metastasis, it is of high importance to identify a universal cancer type-independent signature to better understand cancer pathogenesis and ultimately to improve therapeutics. After such a signature is identified, it could be used as a component of genomic-based clinical diagnostic tools for cancer patients to determine the presence of cancer cells in tissues.

Recently, several studies used meta-analysis methods to identify genes differentially expressed across multiple cancer types [16-18]. In the study of Rhodes et al. [17], 21 published cancer microarray data sets, spanning 12 distinct cancer types, were collected and analyzed in an effort to identify a cancer type-independent transcriptional signature of neoplastic transformation. A statistical metaanalysis method, termed comparative meta-profiling, was proposed to compare and assess the intersection of many cancer type-dependent signatures, the goal being to identify a common cancer meta-signature. The comparative meta-profiling method works as follows. First, an overexpression direction (e.g. cancer $>$ normal) and significant threshold are set to define differential gene expression signatures from a set of cancer versus normal studies (one signature per study). Next, genes are sorted by the number of signatures in which they are present. Finally, a meta-signature is defined as those genes appearing in a given number of signatures [17], where the cutoff is determined by a random simulation. Rhodes et al used this method to identify a set of 67 genes that are universally activated in most cancer types relative to corresponding normal tissues.

One limitation of meta-analysis of microarray data is that small sample sizes typical of individual studies, coupled with variation due to differences in study protocols, inevitably degrades the results of meta-analysis. An additional and major limitation of the comparative meta-profiling method is that those genes which are common to the various array platforms used in these studies are highly overrepresented in the identified meta-signature. This way of defining a meta-signature by gene enrichment in signatures implies that many potentially informative genes which are not common to the various array platforms used in these studies may be overlooked due to the intrinsic properties of this method. As a specific example, the relationship between the numbers of total genes on two major Affymetrix microarray platforms used in the study of Rhodes et al. and the corresponding numbers of genes included in the reported common cancer meta-signature is shown in the Venn diagram of Figure 1. Among the 67 meta-signature genes, 59 genes are on one or both of these two microarray platforms and the other eight genes come from other microarray platforms. Almost all of the 59 meta-signature genes come from the set of 5127 genes which are common across the two microarray platforms employed in this study.

In our previous work, we proposed a novel, simple method, referred to as the top-scoring pair (TSP) classifier, to integrate inter-study microarray data and validated the method on prostate cancer data [14]. It has also been applied recently to differentiating between gastrointestinal stromal tumors and leiomyosarcomas [19]. The TSP method is based only on the ranks of the expression values within a profile and hence there is no need to perform data normalization and transformation before data integration because rankings are invariant to nearly all types of preprocessing. Further, the TSP method identifies only a pair of genes as a gene signature and the decision rule is based simply on comparing their expression values. This approach to data integration was validated on prostate cancer data [14], resulting in a powerful two-gene diagnostic classifier. Here, we extend this method to predict distant metastases in breast cancer, and attempt to overcome the limitations of previous study-specific methods and meta-analyses.

Here, we present a generalization of this method, termed top-scoring pair of groups (TSPG), which preserves the basic properties of the TSP classifier, namely invariance to normalization and comparison-based rules, but incorporates more genes into the decision-making. We apply this generalization to identify a cancer type-independent sig-

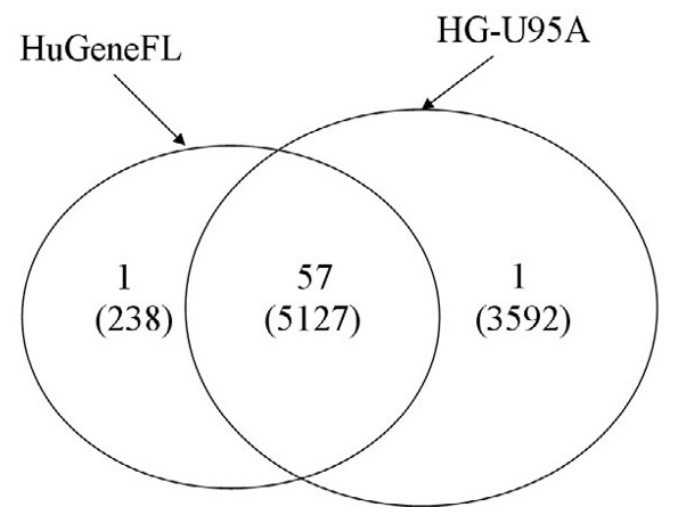

\section{Figure I}

Common genes overrepresented in the meta-signature. The figure shows the relationship between the numbers of genes on two microarray platforms, HuGeneFL and HG-U95A, and the corresponding numbers of genes in the meta-signature of neoplastic transformation [I7]. There are 5127 genes common to both platforms, 238 only on HuGeneFL and 3592 only on HG-U95A. The numbers without parentheses are the corresponding numbers of genes in the meta-signature. 
nature by integrating microarray data from different cancer studies across almost all major human cancer types. This overcomes the limitations of previous meta-analyses by integrating large-scale microarray data generated using the same microarray platform, resulting in one signature per platform (rather than per study) and effectively increasing sample size. Integrating microarray data from the same platform can guarantee that all the genes on the platform will be included in the analysis, therefore avoiding losing any potential signature genes. Moreover, unlike the approach in [17], which requires cross-validation for decision-making, and hence an ensemble of new samples for testing the predictive power of the common signature, the TSPG method provides a classifier in the standard sense of a prediction rule which can be applied to label a single new sample.

By combining the TSPG method and a repeated random sampling strategy, a common cancer signature, which consists of 46 distinct genes, is identified from the integrated microarray data. The TSPG classifier, which dis- criminates cancer from normal samples, is built from the signature and validated on both the training data and independent cancer microarray data. Upon further validation on large-scale independent data, the signature may be used to develop a novel cancer diagnostic tool and provide new insights regarding the mechanism of cancer.

\section{Results \\ Data collection}

Microarray data sets were obtained from public gene expression data repositories, including Gene Expression Omnibus [20], Oncomine [21] and supporting web sites identified from the published literature. In particular, we focused on analysis of human cancer gene expression data obtained using the Affymetrix HuGeneFL, HG-U95A and HG-U133A microarray platforms. Of these collected data, 26 individual data sets generated from HuGeneFL arrays (Table 1) and HG-U95A arrays (Table 2) were used as training data and six individual data sets from HG-U133A arrays (Table 3) were used as independent test data. In total, 1593 microarray experiments from 32 independent

Table I: Microarray data from Affymetrix HuGeneFL arrays

\begin{tabular}{|c|c|c|c|c|}
\hline Study & Class I & Size & Class2 & Size \\
\hline Beer_Lung [25] & Normal Lung & 10 & Lung Adenoarcinoma & 86 \\
\hline Dyrskjot_Bladder [26] & Normal Bladder & 4 & Bladder Cancer & 40 \\
\hline Hippo_Gastric [27] & Normal Gastric Tissues & 8 & Gastric Cancer & 22 \\
\hline Hsiao_Normal [28] & Normal Tisues & 59 & & \\
\hline Lancaster_Ovarian [29] & Normal Ovary & 3 & Ovarian Adenocarcinoma & 31 \\
\hline Logsdon_Pancreas [30] & Normal Pancreas & 5 & $\begin{array}{l}\text { Pancreatic } \\
\text { Adenocarcinoma }\end{array}$ & 10 \\
\hline \multirow[t]{4}{*}{ Pomeroy_Brain [3।] } & Normal Cerebellum & 4 & $\begin{array}{l}\text { Atypical Teratoid/Rhabdoid } \\
\text { Tumors }\end{array}$ & 10 \\
\hline & & & $\begin{array}{l}\text { Primitive neuroectodermal } \\
\text { Tumors }\end{array}$ & 8 \\
\hline & & & Malignant Gliomas & 10 \\
\hline & & & Medulloblastoma & 10 \\
\hline Quade_Myometrium [32] & Normal Myometrium & 4 & Leiomyosarcoma & 14 \\
\hline \multirow[t]{14}{*}{ Ramaswamy_Multi [33] } & Normal Prostate & 9 & Prostate Cancer & 10 \\
\hline & Normal Uterus & 6 & Uterine Cancer & 10 \\
\hline & Normal Whole brain & 8 & $\begin{array}{l}\text { Glioblastoma/ } \\
\text { Medulloblastoma }\end{array}$ & 20 \\
\hline & Normal Breast & 5 & Breast Adenocarcinoma & II \\
\hline & Normal Lung & 7 & Lung Adenoarcinoma & 11 \\
\hline & Nromal Colon & II & Colorectal & 11 \\
\hline & Normal Germinal Center & 6 & Lymphoma & 22 \\
\hline & Normal Bladder & 7 & Bladder Cancer & 11 \\
\hline & & & Melanoma & 10 \\
\hline & Peripheral Blood & 5 & Leukemia & 30 \\
\hline & Normal Kidney & 12 & Renal Cell Carcinoma & 11 \\
\hline & Normal Pancreas & 10 & $\begin{array}{l}\text { Pancreatic } \\
\text { Adenocarcinoma }\end{array}$ & $\mathrm{II}$ \\
\hline & Normal Ovary & 4 & Ovarian Carcinoma & II \\
\hline & & & Mesothelioma & 11 \\
\hline Rickman_Brain [34] & Normal Temporal Lobe & 6 & Glioma & 45 \\
\hline Welsh_Ovarian [35] & Normal Ovary & 4 & Ovarian Carcinoma & 22 \\
\hline Zhan_Myeloma [36] & $\begin{array}{l}\text { Normal Plasma Cell- Bone } \\
\text { Marrow }\end{array}$ & 30 & Multiple Myeloma & 74 \\
\hline Total & Normal Tissues & 227 & Cancer Tissues & 572 \\
\hline
\end{tabular}


Table 2: Microarray data from Affymetrix HG-U95A arrays

\begin{tabular}{|c|c|c|c|c|}
\hline Study & Class I & Size & Class2 & Size \\
\hline \multirow[t]{3}{*}{ Bhattacharjee_Lung [37] } & Normal Lung & 17 & Small Cell Lung Carcinoma & 6 \\
\hline & & & Lung Carcinoid & 20 \\
\hline & & & $\begin{array}{l}\text { Squamous Cell Lung } \\
\text { Carcinoma }\end{array}$ & 21 \\
\hline Cromer_Head-Neck [38] & Normal Uvula & 4 & $\begin{array}{l}\text { Head-Neck Squamous Cell } \\
\text { Carcinoma }\end{array}$ & 34 \\
\hline \multirow[t]{3}{*}{ Dehan_Lung [39] } & Normal Lung & 9 & Lung Adenocarcinoma & 7 \\
\hline & & & $\begin{array}{l}\text { Lung Squamous Cell } \\
\text { Carcinoma }\end{array}$ & 17 \\
\hline & & & Lung Adenosquamous & 1 \\
\hline Frierson_Salivary [40] & Normal Salivary Gland & 6 & Salivary Carcinoma & 16 \\
\hline Giordano_Adrenal [4I] & Normal Adrenal Cortex & 3 & Adrenocortical Carcinoma & 11 \\
\hline Gutmann_Brain [42] & Normal White Matter & 3 & Pilocytic Astrocytoma & 8 \\
\hline Huang_Thyroid [43] & Normal Thyroid & 8 & Thyroid Carcinoma & 8 \\
\hline Shai_Brain [44] & White Matter & 7 & Glioblastoma Multiforme & 35 \\
\hline Stearman_Lung [45] & Normal Lung & 19 & Lung Tumor & 20 \\
\hline Su_Multi ${ }^{[46]}$ & Normal Tissues & 63 & Tumor Tissues & 18 \\
\hline \multirow[t]{11}{*}{ Su_Tumors [5] } & & & Prostate Cancer & 24 \\
\hline & & & Bladder/Ureter & 8 \\
\hline & & & Breast & 21 \\
\hline & & & Colorectal & 21 \\
\hline & & & Gastroesophagus & 11 \\
\hline & & & Kidney & 10 \\
\hline & & & Liver & 6 \\
\hline & & & Ovary & 23 \\
\hline & & & Pancreas & 6 \\
\hline & & & Lung Adenocarcinoma & 12 \\
\hline & & & $\begin{array}{l}\text { Lung Squamous Cell } \\
\text { Carcinoma }\end{array}$ & 12 \\
\hline Welle_Normal [47] & Normal Muscle & 12 & & \\
\hline Yanai_Normal [48] & Normal Tissues & 24 & & \\
\hline Yu_Prostate [49] & Normal Prostae & 16 & $\begin{array}{l}\text { Primary Prosate } \\
\text { Carcinoma }\end{array}$ & 35 \\
\hline Total & Normal Tissues & 191 & Cancer Tissues & 411 \\
\hline
\end{tabular}

Table 3: Microarray data from Affymetrix HG-UI33A arrays

\begin{tabular}{|c|c|c|c|c|}
\hline Study & Class I & Size & Class2 & Size \\
\hline \multirow[t]{2}{*}{ Gordon_Lung [50] } & Normal Lung & 4 & $\begin{array}{l}\text { Malignant Pleural } \\
\text { Mesothelioma }\end{array}$ & 40 \\
\hline & Normal Pleura & 5 & & \\
\hline Hoffman_Myometrium [5!] & Normal Myometrium & 5 & Uterine Leiomyomas & 5 \\
\hline Lenburg_Kidney [52] & Normal Kidney Tissue & 5 & Renal Cell Carcinoma & 12 \\
\hline Talantov_Skin [53] & Normal Skin & 7 & Melanoma & 45 \\
\hline Wachi_Lung [54] & Normal Lung & 5 & Squamous Lung Cancer & 5 \\
\hline Yoon_Soft_Tissue [55] & Normal Soft Tissue & 15 & Soft Tissue Sarcoma & 39 \\
\hline Total & Normal Tissues & 46 & Cancer Tissues & 146 \\
\hline
\end{tabular}


studies across almost all human cancer types were used in this analysis. Studies are named using the same convention as in [17]: FirstAuthor_Tissue (e.g. Beer_Lung).

\section{Common cancer signature}

We directly merge 12 (respectively, 14) cancer/normal microarray data sets generated from Affymetrix HuGeneFL (respectively, HG-U95A) (Table 1 and 2), using the common 7069 (respectively, 12532) probe sets among all these data sets to form an integrated training data set with 799 (respectively, 602) samples. These data sets span 21 tissue types including lung, breast, bladder, ovarian, pancreas, brain, prostate, uterus, colon, blood, kidney, uvula, salivary gland, thyroid gland, liver, skin, gastric tissue, myometrium, bone marrow, adrenal cortex and gastroesophagus. For each of the two integrated data sets, we randomly select $S \%=90 \%$ of the total samples from the integrated data set and then apply the TSPG algorithm to the selected data to construct two groups, $G_{1}$ and $G_{2}$, of genes. After the experiment is repeated 1000 times, the appearance frequency for each gene which is present in any of the $1000 G_{1}$ 's (respectively, $G_{2}$ 's) is calculated. For the default frequency threshold $F=80 \%$, the appearance frequency of 24 genes (13 in $G_{1}$ and 11 in $G_{2}$ ) from the HuGeneFL integrated data set and 25 genes ( 12 in $G_{1}$ and 13 in $G_{2}$ ) from the HG-U95A integrated data set exceeds $F$ (Table 4). There are three genes (CLEC3B, COX7A1 and KIAA0101) which are selected from both integrated data sets. Therefore, a common cancer signature, which consists of the 46 genes ( 24 in $G_{1}$ and 22 in $G_{2}$ ) obtained from the two integrated data sets, is identified from the integrated microarray data. For $F=90 \%$ and $70 \%$ the common cancer signatures consist of slightly different genes. (For $F=90 \%, 39$ out of the above 46 genes appear and for $F=70 \% 10$ more genes are added to the 46 genes.) For the rest of this paper, we will focus on the 46-gene common cancer signature corresponding to $F=80 \%$.

\section{Validation of the common cancer signature on the training data}

To validate the reliability and robustness of the common cancer signature, the TSPG classifier, which predicts cancer vs. normal status, is built based on all the signature genes, with 24 genes in $G_{1}$ and 22 genes in $G_{2}$ as indicated above. The classification rule for the TSPG classifier is that if the average relative rank of the genes in $G_{1}$ is less than

Table 4: Common cancer signature genes

\begin{tabular}{|c|c|c|c|c|}
\hline \multirow[t]{2}{*}{ Microarray Platform } & \multicolumn{2}{|c|}{$G_{1}$} & \multicolumn{2}{|c|}{$G_{2}$} \\
\hline & Gene Symbol & Probe Set ID & Gene Symbol & Probe Set ID \\
\hline \multirow[t]{13}{*}{ HuGeneFL } & BOPI & D509|4_at & COX7AI & M83186_at \\
\hline & PON2 & L485I3_at & CXCLI2 & U19495_s_at \\
\hline & NMEI* & X17620_at & ALDHIAI & M31994_at \\
\hline & CKS2* & X54942_at & SELP & M25322_at \\
\hline & ССТЗ & X7480I_at & CD36 & Z32765_at \\
\hline & KIAAOIOI* & DI4657_at & CSRPI & M76378_at \\
\hline & FOXMI & U74612_at & C9orf6I & L27479_at \\
\hline & MAP3KII & L32976_at & MYHII & AF001548_rnal_at \\
\hline & RABI3 & X75593_at & LTC4S & U50136_rnal_at \\
\hline & ARPCIB & AF006084_at & DEFA4 & X65977_at \\
\hline & HMGAI & LI7I3I_rnal_at & CLEC3B & X64559_at \\
\hline & TYMS & D00596_at & & \\
\hline & DNMTI & X63692_at & & \\
\hline \multirow[t]{13}{*}{ HG-U95A } & soX4* & 33|3|_at & TEK & 1596_g_at \\
\hline & C7orf24 & 41696_at & FXYDI & $32109 \_$at \\
\hline & POSTN & |45I_s_at & ABCA8 & 35717_at \\
\hline & BAZIB & 3226I_at & CLEC3B & 36569_at \\
\hline & KIAAOIOI* & 38116_at & $\mathrm{CB} \times 7$ & 36894_at \\
\hline & RECQL & 34684_at & $\mathrm{TN} \times \mathrm{A} / / / \mathrm{TN} \times \mathrm{B}$ & 38508_s_at \\
\hline & FAT & 40454_at & SH3BP5 & 38968_at \\
\hline & SIPAIL3 & 37831_at & CA4 & 40739_at \\
\hline & MARCKSLI & 36174_at & FBXO9 & 38990_at \\
\hline & CKAP4 & 32529_at & COX7AI & 39031_at \\
\hline & $\mathrm{KIFI} 4$ & 34563_at & GABARAPLI & 35785_at \\
\hline & SUBI & 36171_at & ADHIB & 35730_at \\
\hline & & & PTGDS & 216_at \\
\hline
\end{tabular}

* These genes were also identified as common cancer signature genes in Rhode et al. [17]. 
that of the genes in $G_{2}$, a test sample is classified as normal; otherwise it is classified as cancer. The expression values of the 46 signature genes are illustrated in Figure 2 using some of the training data, including Stearman_Lung, Frierson_Salivary, Giordano_Adrenal and Gutmann_Brain data sets. Distinct patterns of expression values of the genes in $G_{1}$ and $G_{2}$ can be observed for normal and cancer samples. The classifier is then used to assess the prediction accuracy of the signature on the training data sets spanning a wide range of cancer types. For the 26 individual data sets which have been integrated and used to identify the signature, the classification accuracy and the $p$-values of the Fisher's exact test are shown in Table 5 . The classifier achieves high accuracy ( $>85 \%$ ) on 19 of 26 data sets and the overall accuracy is about $86 \%$. From the $p$-values of the Fisher's exact test, we learn that the classification is significant ( $p$-value $<0.03$ ) on 18 of 22 data sets. There is no $p$-value available for four data sets which only have samples from one class. The classifier is both significant ( $p$-value $<0.03$ ) and accurate $(>85 \%)$ on 14 of 22 data sets. The results suggest that we have identified a common cancer signature for most, if not all, human cancer types.

\section{Validation of the common cancer signature on independent test data}

To further validate the generality and robustness of the common cancer signature, the TSPG classifier built based on the signature is tested on six independent test data sets generated from a different generation of Affymetrix microarray platforms, HG-U133A (Table 3). The six independent data sets represent six different human cancer types,

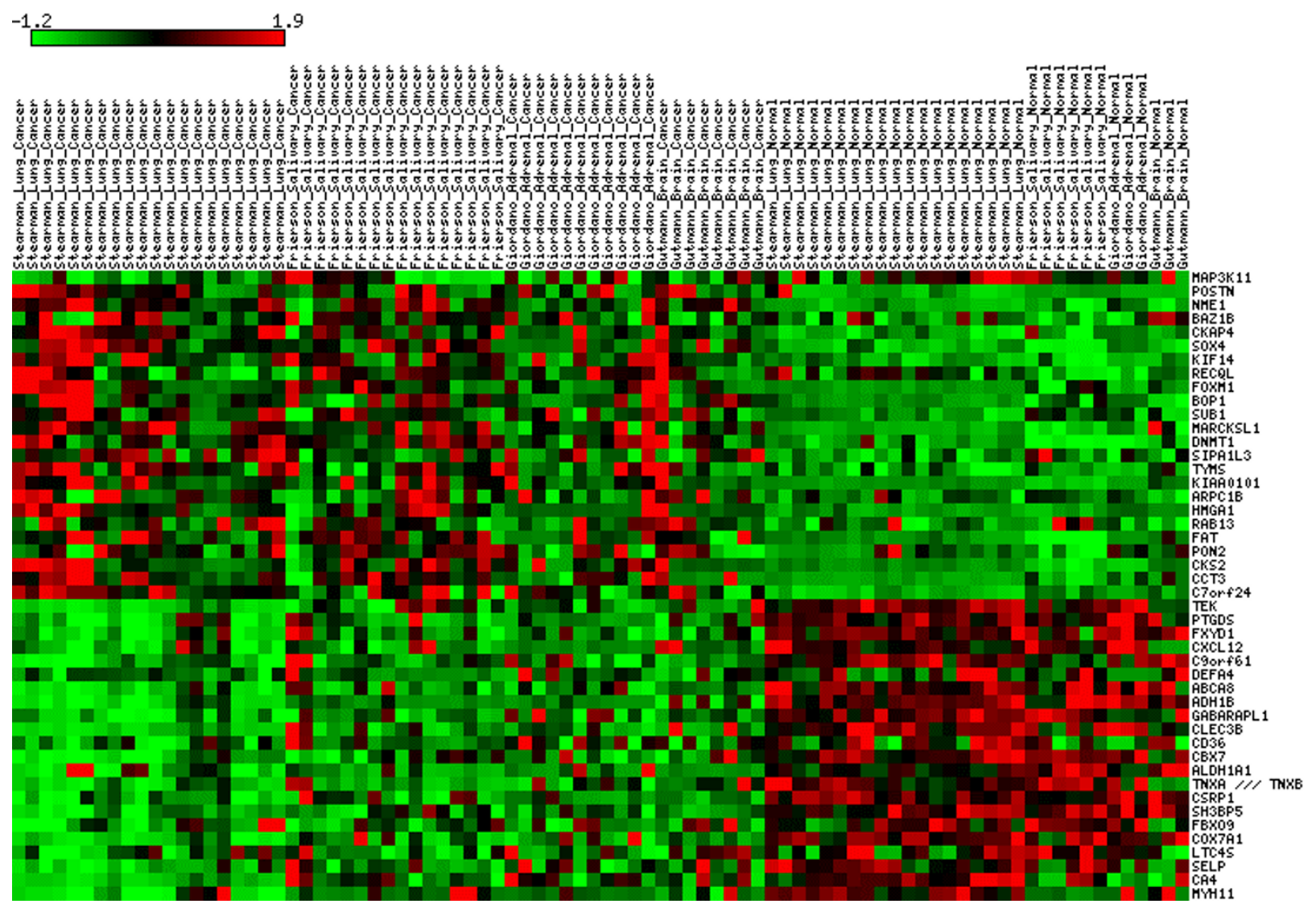

Figure 2

Common cancer signature which can discriminate cancer from normal samples. Some of the training data (Stearman_Lung, Frierson_Salivary, Giordano_Adrenal and Gutmann_Brain) is used to illustrate the gene expression values of the signature genes in the figure. The heatmap is generated by the matrix2png software [24]. For each data set, the expression value for each gene is normalized across the samples to zero mean and one standard deviation (SD) for visualization purposes. Genes with expression levels greater than the mean are colored in red and those below the mean are colored in green. The scale indicates the number of SDs above or below the mean. 
Table 5: Class prediction of the common signature on training data

\begin{tabular}{|c|c|c|c|c|c|}
\hline Microarray Platform & Study & $\begin{array}{c}\text { Number of Normal } \\
\text { Samples }\end{array}$ & $\begin{array}{c}\text { Number of Cancer } \\
\text { Samples }\end{array}$ & Accuracy (\%) & $P$-value \\
\hline \multirow[t]{13}{*}{ HuGeneFL } & Beer_Lung & 10 & 86 & 95.8 & 8.87E-II \\
\hline & Dyrskjot_Bladder & 4 & 40 & 95.5 & I.18E-03 \\
\hline & Hippo_Gastric & 8 & 22 & 76.7 & 2.67E-0I \\
\hline & Hsiao_Normal & 59 & 0 & 91.5 & N/A* \\
\hline & Lancaster_Ovarian & 3 & 31 & 91.2 & 1.00 \\
\hline & Logsdon_Pancreas & 5 & 10 & 100 & $3.33 \mathrm{E}-04$ \\
\hline & Pomeroy_Brain & 4 & 38 & 97.6 & $3.48 \mathrm{E}-04$ \\
\hline & Quade_Myometrium & 4 & 14 & 77.8 & $2.29 \mathrm{E}-02$ \\
\hline & Ramaswamy_Multi & 90 & 190 & 77.9 & I.28E-20 \\
\hline & Rickman_Brain & 6 & 45 & 94.1 & 2.87E-04 \\
\hline & Welsh_Ovarian & 4 & 22 & 100 & $6.69 \mathrm{E}-05$ \\
\hline & Zhan_Myeloma & 30 & 74 & 72.1 & $2.88 \mathrm{E}-0 \mathrm{I}$ \\
\hline & $\begin{array}{l}\text { Overall } \\
\text { (HuGeneFL) }\end{array}$ & 227 & 572 & 85.0 & 6.70E-68 \\
\hline \multirow[t]{15}{*}{ HG-U95A } & Bhattacharjee_Lung & 17 & 47 & 90.6 & $6.34 \mathrm{E}-10$ \\
\hline & Cromer_Head-Neck & 4 & 34 & 97.4 & 4.74E-04 \\
\hline & Dehan_Lung & 9 & 25 & 85.3 & $3.82 \mathrm{E}-05$ \\
\hline & Frierson_Salivary & 6 & 16 & 95.5 & $9.38 \mathrm{E}-05$ \\
\hline & Giordano_Adrenal & 3 & 11 & 92.9 & I.10E-02 \\
\hline & Gutmann_Brain & 3 & 8 & 100 & $6.06 \mathrm{E}-03$ \\
\hline & Huang_Thyroid & 8 & 8 & 75 & 5.59E-02 \\
\hline & Shai_Brain & 7 & 35 & 85.7 & $6.36 \mathrm{E}-05$ \\
\hline & Stearman_Lung & 19 & 20 & 89.7 & I.28E-07 \\
\hline & Su_Multi & 63 & 18 & 81.5 & I.15E-05 \\
\hline & Su_Tumors & 0 & 154 & 93.5 & N/A \\
\hline & Welle_Normal & 12 & 0 & 100 & $\mathrm{~N} / \mathrm{A}$ \\
\hline & Yanai_Normal & 24 & 0 & 91.7 & $\mathrm{~N} / \mathrm{A}$ \\
\hline & Yu_Prostate & 16 & 35 & 54.9 & $1.83 \mathrm{E}-02$ \\
\hline & $\begin{array}{l}\text { Overall (HG- } \\
\text { U95A) }\end{array}$ & 191 & 411 & 87.0 & 3.65E-77 \\
\hline
\end{tabular}

* For the data sets with samples from only one class, no $p$-value is available.

one of which is not represented in the training data sets (Yoon_Soft_Tissue). The classification accuracy and statistical significance (i.e. $p$-value of the Fisher's exact test) of the common cancer signature are listed in Table 6 . The signature significantly ( $p$-value $<0.005$ ) discriminates cancer from normal samples with very high accuracy ( $>95 \%)$ on four of the six data sets, including the new cancer type data set. On the other two data sets, the signature achieves much higher accuracy (> 75\%) than that of coin-flipping but only marginally significant ( $p$-value $=0.083$ and $0.107)$. The independent test results have validated that the signature is common to a wide range of cancer types and may be used to detect the presence of cancer cells in tissues.

\section{Comparison with the Rhodes signature}

We compare our common cancer signature to the one for meta-signature of neoplastic transformation reported in

Table 6: Validation of the common signature on independent HG-UI33A data

\begin{tabular}{|c|c|c|c|c|}
\hline Study & $\begin{array}{c}\text { Number of Normal } \\
\text { Samples }\end{array}$ & $\begin{array}{c}\text { Number of Cancer } \\
\text { Samples }\end{array}$ & Accuracy (\%) & $P$-value \\
\hline Gordon_Lung & 9 & 40 & 95.9 & I.75E-07 \\
\hline Hoffman_Myometrium & 5 & 5 & 80.0 & $8.33 \mathrm{E}-02$ \\
\hline Lenburg_Kidney & 5 & 12 & 76.5 & I.07E-0 I \\
\hline Talantov_Skin & 7 & 45 & 98.1 & $3.44 \mathrm{E}-07$ \\
\hline Wachi_Lung & 5 & 5 & 100 & 3.97E-03 \\
\hline Yoon_Soft_Tissue & 15 & 39 & 96.3 & $6.76 \mathrm{E}-\mathrm{II}$ \\
\hline Overall & 46 & 146 & 94.3 & $9.74 E-30$ \\
\hline
\end{tabular}


[17]. It is not surprising that there is a small overlap between the two signatures with four common genes (see Table 4). On the one hand, this implies that both studies have identified some molecular features common to all cancer types. On the other hand, the difference between the two signatures may result from the two major differences between the two methods. First, the comparative meta-profiling method overlooks a large number of potential signature genes due to its intrinsic properties whereas our method includes all possible genes in the analysis. Second, the analysis in [17] focuses on differentially expressed genes; more specifically, it chooses genes which are over-expressed in one direction (cancer $>$ normal). In contrast, our selection criterion is not based on differential expression, but rather on finding pairs of genes whose expression values typically invert from cancer to normal tissues. One consequence is that our signature includes genes over-expressed in both directions, as illustrated in Figure 2, as well as genes which are not differentially expressed.

We then compare the classification performance of the two signatures on the same independent test data. Results are reported in Table 7. In this way the two signatures and corresponding cancer prediction rules are evaluated on completely independent data not involved in learning either signature. Significantly, the approach in Rhodes [17] does not provide a well-defined classifier corresponding to the signature; important aspects of the classifier must be learned on the test data, producing an upwardlybiased estimate of classification accuracy. (A more complete explanation appears in "Methods.") Nonetheless, the TSPG classifier based on our common signature outperforms the classifier based on the Rhode signature [17] on three of the six independent test data sets and achieves the same accuracy on the other three data sets. Unlike the Rhodes classifier, the TSPG classifier is completely determined by the signature itself and was applied sample-bysample to the test data; no learning on the test data was involved.

\section{Discussion}

The advent of DNA microarray has had a tremendous impact on cancer research. This technology provides a novel molecular tool, complementary to histopathologic examination, to assess the presence of cancer cells in patient tissues. The rapid accumulation of cancer microarray data makes it possible to integrate a large amount of microarray gene expression data across a wide range of cancer types to identify a universal cancer signature to detect cancer cells, regardless of the tissue from which the cancer is derived. In this study, by integrating microarray data and applying the TSPG method combined with repeated random sampling, we have identified a robust cancer gene expression signature common to almost all major human cancer types. The discriminative power of the signature has been validated on both data sets involved in identifying the signature and independent test data sets. The TSPG classifier built from the signature, which simply compares the average relative ranks of two groups of genes, achieves high accuracy on most of the training and test data sets with statistical significance. Although the signature has the potential to be developed as a robust and objective clinical diagnostic test for cancer, larger number of samples will be required to further refine and validate it.

An intriguing advantage of inter-study cancer microarray data integration is that it increases the statistical power to capture essential, cancer type-independent gene expression features, which might be masked by specific features of individual cancer types and small sample sizes of individual data sets. In this sense, the signature is reliable and robust to variations in individual cancer data sets. The universal cancer signature described here may play a crucial role in oncogenic processes and be used to improve our understanding of cancer pathogenesis and ultimately design improved anticancer treatments. It also suggests the possible existence of therapeutic targets common to different cancer types.

Table 7: Comparison with the Rhodes signature on the same independent data

\begin{tabular}{lcccc}
\hline Study & \multicolumn{2}{c}{ Rhodes Signature } & Our Signature \\
\cline { 2 - 5 } & Accuracy (\%) & P-value & Accuracy (\%) & $P$-value \\
\hline Gordon_Lung & 91.8 & $3.48 \mathrm{E}-07$ & 95.9 & $1.75 \mathrm{E}-07$ \\
Hoffman_Myometrium & 80.0 & $2.06 \mathrm{E}-01$ & $8.33 \mathrm{E}-02$ \\
Lenburg_Kidney & 76.5 & $1.01 \mathrm{E}-01$ & $1.07 \mathrm{E}-01$ \\
Talantov_Skin & 94.2 & $8.97 \mathrm{E}-07$ & $3.44 \mathrm{E}-07$ \\
Wachi_Lung & 100 & $3.97 \mathrm{E}-03$ & 98.5 & $3.97 \mathrm{E}-03$ \\
Yoon_Soft_Tissue & 85.2 & $5.67 \mathrm{E}-8$ & 100 & $6.76 \mathrm{E}-11$ \\
\hline Overall & $\mathbf{8 9 . 1}$ & $\mathbf{9 . 2 8 E - 2 6}$ & 96.3 & $\mathbf{9 4 . 3}$ \\
\hline
\end{tabular}


We have observed that the signature seems to perform better for certain tissue types, such as lung, skin, and soft tissue cancer. There are many possible reasons to cause the different performance of the signature on different cancer types. These reasons may include differences in sample composition and preparation, experimental protocols, RNA quality, proportion of cancer cells in a tissue, and microarray quality. In addition, some cancer types might be easier to detect than other cancer types.

It is not surprising that many of the signature genes (BOP1, KIAA0101, CCT3, ARPC1B, CKAP4, ALDH1A1, CD36, CLEC3B, TEK, CBX7) have been reported to be associated with specific types of cancer in the literature and some other genes (NME1, TYMS, POSTN, FOXM1, HMGA1, DNMT1, KIF14, CXCL12, SELP) have been previously found to be associated with a variety of distinct human cancer types. As defined by Gene Ontology Consortium, the common signature genes are involved in cell cycle (MAP3K11, NME1, CKS2, MYH11), regulation of transcription (BAZ1B, SOX4, FOXM1, SUB1, CBX7, DNMT1, HMGA1, RAB13), DNA metabolism (RECQL, CBX7, DNMT1, TYMS, HMGA1), cellular biosynthesis (NME1, PTGDS, KIF14, TYMS, LTC4S), cellular protein metabolism (MAP3K11, TEK, KIF14, FBXO9, HMGA1, CCT3) and other important biological processes, such as cell organization and cell adhesion. These findings are consistent with the fact that all cancer types share the common features of uncontrollable cell growth and local tissue invasion, and therefore the genes that are essential to these cellular processes are possible signature genes among almost all cancer types.

One limitation of our proposed method for microarray data integration is that it can only directly integrate microarray data generated from the same standard microarray platforms. Even with this limitation, we still obtain a large number of samples ( $>500)$ on each of the two microarray platforms used in this study. With the rapid increase of available microarray data and the standardization of microarray technologies, the mass of microarray data generated from the same platforms will continue to grow, which will make our method become increasingly useful.

It is quite interesting that a similar study on common cancer biomarkers was published very recently [22]. The uniqueness of the study is that the researchers have generated microarray data across various cancer types using the same spotted cDNA microarray, and therefore no data integration is needed. By applying a gene pairing method to a training set with 201 samples of various normal and cancer tissues, a subset of 14 genes identified as common cancer biomarkers with high predictive power $(87 \%)$ in segregating cancer from normal samples. Two of the 14 genes, PON2 and SOX4, have also been identified in our common cancer signature. The major limitation of the study is that the cancer samples are dominated by only a few cancer types (colon, melanoma, ovarian and esophageal cancers). Therefore, the biomarkers identified in the study may not really be common to a broad range of cancer types. In our study, motivated by the work of Rhodes et al., we collected a broader range of microarray gene expression data for about 20 cancer types and each of them is reasonably represented in the training data sets. The signature identified in our study has been validated on independent data sets of various cancer types, including one cancer type which is not represented in the training data sets.

Finally, we have also compared our classifier with the method in Rhodes et al. on the same test sets; in this way the two signatures and corresponding cancer prediction rules are evaluated on completely independent data not involved in learning either signature. In classifying a test sample, the Rhodes classifier must use all the other samples in the same test set to compute class averages; hence cross-validation is necessary. In contrast, our classifier operates in the conventional way, classifying each sample independently of all others. Despite this source of bias in the Rhodes classifier, our method still achieves higher overall accuracy.

\section{Conclusion}

In conclusion, by combining large-scale microarray data, a robust common cancer signature has been identified. Upon more large-scale validation, it could be developed as a component of genomic-based clinical diagnostic tools for cancer patients. Further studies of the signature might also improve our understanding of cancer and identify new drug targets.

\section{Methods TSPG classifier}

Recently, our group has developed a family of statistical molecular classification methods, referred to as the TSP and the $k$-TSP classifiers $[13,15]$, and applied the TSP classifier to microarray data integration [14]. These methods only use the ranks of gene expression values within each profile and achieve impressive results in both molecular classification and microarray data integration [13-15]. An important feature of rank-based methods is that they are invariant to monotonic transformations of the expression data within an array, such as those used in most data normalization methods. This property makes these methods useful for combining inter-study microarray data without the need to perform data normalization and transformation. Here, we present a similar but more robust method, termed the TSPG classifier, in order to identify a gene expression signature common to a wide range of cancer types by integrating large-scale cancer microarray data. 
The development of the TSPG method is motivated by following considerations. It is known that many genes are involved in the oncogenic processes; therefore, in order to better understand cancer pathogenesis, we need to identify a common cancer signature which consists of more than just a few genes. The TSP method previously used only identifies a pair of signature genes, say $i$ and $j$, which obviously cannot constitute an effective common cancer signature. The basic idea it to replace $i$ and $j$ by two groups $G_{1}$ and $G_{2}$ of genes, but preserve the property of basing prediction on expression comparisons as well as the scoring mechanism. Instead of simply comparing the ranks of the expression values of genes $i$ and $j$, we rank all the genes in the two groups $G_{1}$ and $G_{2}$ and compare the average ranks $G_{1}$ and $G_{2}$. When each group consists of a single gene, the TSPG method reduces to TSP.

Another motivation for developing the TSPG method is related to the observation that, in some cases, one gene may pair with different genes to form a top-scoring pair when the training data is perturbed by adding or deleting a few samples. This may imply that a gene consistently appearing in top-scoring pairs may be closely correlated to cancer whereas the other genes occasionally paired with it might be irrelevant to cancer. We want to keep those genes which may play a crucial role in oncogenic processes in the common cancer signature and eliminate those genes which may be irrelevant to cancer. When combined with repeated random sampling, the TSPG method provides the flexibility to keep one gene of a TSP in a signature while excluding the other one from it.

The TSPG classifier is defined as follows. Assume the training microarray data are represented by a $P \times N$ matrix $X=$ $\left[X_{p n}\right], p=1,2, \ldots, P$ and $n=1,2, \ldots, N$, where $P$ is the number of genes in each profile and $N$ is the number of samples (i.e. profiles). Each column $n$ represents a gene expression profile of $P$ genes with a class label $Y_{n}=1$ (normal) or 2 (cancer) for the two-class problem (normal vs. cancer) in this study. Among the $N$ samples, there are $N_{1}$ (respectively, $N_{2}$ ) samples labeled as class 1 (respectively, class 2) with $N=N_{1}+N_{2}$. For each pair of genes $(i, j)$, where $i, j=1,2, \ldots, P, i \neq j$, we define a score as

$$
\Delta_{i j}=\left|P\left(X_{i}<X_{j} \mid Y=1\right)-P\left(X_{i}<X_{j} \mid Y=2\right)\right|
$$

and estimate the score based on the training set $X$ by

$$
\Delta_{i j} \approx\left|\frac{N_{i j}^{(1)}}{N_{1}}-\frac{N_{i j}^{(2)}}{N_{2}}\right|
$$

where

$$
N_{i j}^{(k)}=\left|\left\{n: 1 \leq n \leq N, X_{i n}<X_{j n}, Y_{n}=k\right\}\right|, k=1,2 .
$$

For those pairs that achieve an identical score, we use a secondary score, called the rank-score, to break the tie $[14,15]$. The rank-score takes into account the extent to which a gene pair inverts from one class to the other. For each pair $(i, j)$, the rank-score, denoted by $\delta_{i j}$, is defined as

$\delta_{i j}=\left|\frac{1}{N_{1}} \sum_{n \in\left\{m: 1 \leq m \leq N, Y_{m}=1\right\}}\left(R_{i n}-R_{j n}\right)-\frac{1}{N_{2}} \sum_{n \in\left\{m: 1 \leq m \leq N, Y_{m}=2\right\}}\left(R_{i n}-R_{j n}\right)\right|$.

Here $R_{i n}$ is the rank of the expression value of gene $i$ within the $n$-th profile in ascending order.

The TSPG algorithm constructs two disjoint groups (or sets) of genes, $G_{1}$ and $G_{2}$, with $\left|G_{1}\right|+\left|G_{2}\right|<<$, where $\left|G_{l}\right|$ denotes the number of genes in group $G_{l,} l=1,2$. The classifier makes a prediction based on the average relative ranks of the genes in the two groups. The decision rule of the classifier is based on all the genes in $G_{1}$ and $G_{2}$. Let $W_{i^{\prime}}$ $i \in G=G_{1} \cup G_{2}$, be the relative ranks of the genes within $G$ in ascending order and let $E$ denote the event that the average relative rank of the genes in $G_{1}$ is less than that of the genes in $G_{2}$, that is,

$$
E=\left\{\frac{1}{\left|G_{1}\right|} \sum_{i \in G_{1}} W_{i}<\frac{1}{\left|G_{2}\right|} \sum_{j \in G_{2}} W_{j}\right\} .
$$

The decision rule of the TSPG classifier is then very simple: Given a test sample $X=\left[X_{1}, \ldots, X_{P}\right]$, if we observe that event $E$, then the classifier selects class 1 ; otherwise, it selects class 2 . Notice the decision rule is based only on the relative ordering among the transcript abundances for the genes in $G$.

Ideally, the two groups of genes in the TSPG algorithm would be determined by maximizing a score analogous to (1), but with the event $\left\{X_{i}<X_{j}\right\}$ replaced by $E$. Needless to say, this is an intractable optimization problem as it would involve optimizing over all pairs of subsets of genes. Instead, we do something sub-optimal but simple: we construct the groups directly from the $k$ top-scoring pairs of genes, where we fix $k=20$; no other values of $k$ were attempted, although performance could likely be improved by choosing $k$ based on cross-validation. Specifically, we first form a list of gene pairs, sorted from the largest to the smallest according to their scores $\Delta_{i j}$, with ties (if there are any) broken by using the rank-score $\delta_{i j}$. 
Next, the $k$ disjoint top-scoring pairs are selected from the list. (In the $k$-TSP classifier [15], a decision is made by simple voting among the $k$ top-scoring pairs.) Finally, we assign each of these selected genes to either $G_{1}$ or $G_{2}$. For each pair $(i, j)$ among the $k$ selected pairs, if $N_{i j}^{(2)} / N_{2}<N_{i j}^{(1)} / N_{1}$, then gene $i$ is assigned to $G_{1}$ and gene $j$ is assigned to $G_{2}$; otherwise, gene $j$ is assigned to $G_{1}$ and gene $i$ is assigned to $G_{2}$. In this way, the genes assigned to $G_{1}$ tend to be expressed less than those assigned to $G_{2}$.

\section{Data integration}

Since rank is invariant to within-array monotonic data transformations, by applying the rank-based TSPG method, which performs on-chip comparisons within each microarray, no data normalization and transformations are required before integration. For microarray data generated from the same platform, we directly merge individual data sets using the common probe sets across all the data sets to form an integrated data set of increased sample size. To merge data from different generations of the same array technology, we first select the common probe sets across the platforms and then merge data using the common probe sets. In that case, a large number of genes, which are not in the common set and may include potential signature genes, will be excluded from analysis. In this study, we focus on integrating microarray data generated using same platform to avoid losing any potential signature genes. Specifically, we integrate microarray data generated from both Affymetrix HuGeneFL and HG-U95A microarray platforms to form two corresponding integrated data sets with large $(>500)$ sample sizes. These two integrated data sets are used as training data sets to identify a common cancer signature.

\section{Repeated random sampling and signature gene selection}

A recent study by Michiels $e t$ al. has shown that molecular signatures strongly depend on the selection of patient samples in the training sets and they advocate the use of repeated random sampling for signature validation [23]. Motivated by their work, we combine the TSPG algorithm with a repeated random sampling strategy in order to obtain a more robust and reliable common cancer signature. We randomly select $S \%$ of the total samples from an integrated training set, with $S$ chosen close to 100 , specifically $S=90$, in order to reasonably represent the original training samples. We then apply the TSPG algorithm to the selected subset of the original training set to construct two groups, $G_{1}$ and $G_{2}$, of genes, with a predefined value of $k$, the number of genes in each group. After repeating this experiment a large number of times, we calculate the appearance frequency of each gene in $G_{l}, l=1,2$. A fre- quency threshold $F$ (default, $F=80 \%$ ) is set to select those genes whose appearance frequency exceeds the threshold in $G_{l} l=1,2$. The final common cancer signature consists of all the genes picked from $G_{1}$ and $G_{2}$ for each of the two integrated training data sets, HuGeneFL and HG-U95A.

\section{Class prediction}

To assess the classification accuracy of the common cancer signature, we build a TSPG classifier based on all the signature genes. The signature genes picked up from $G_{1}$ 's (respectively, $G_{2}$ 's) of the two integrated training sets by repeated random sampling form the group $G_{1}$ (respectively, $G_{2}$ ) of the TSPG classifier. The classifier votes for class 1 (i.e. normal) if the average relative rank of the genes in $G_{1}$ is less than that of the genes in $G_{2}$; otherwise, it votes for class 2 (i.e. cancer). We not only use the classifier to predict samples from data sets involved in identifying the signature, but also validate it on independent data sets. A Fisher's exact test is used to assess the significance of the classification accuracy. The classification accuracy, as well as its statistical significance, is reported for all the individual data sets, training and test.

In Table 7 we compared the TSPG classifier with the one described in Rhodes [17], which requires the existence of an ensemble of samples to learn class averages for each gene in the signature. A new sample is then classified according to the class (cancer or normal) which receives the most votes in comparing the new expression values to these two averages, one comparison per gene in the signature. Moreover, these class averages cannot be computed from the same training data from which the signature is induced since the signature is derived from combining multiple signatures derived from different data sets with differing probe sets. Hence, the only choice for testing the Rhodes signature is cross-validation on a test set, which confers a considerable advantage due to the overall homogeneity of the profiles in each test set (e.g., removing any normalization issues), resulting in an upward bias in the classification rates.

\section{Authors' contributions}

LX, under the supervision of RLW and DG, collected the microarray data sets and implemented the algorithms; all three authors developed the methodology and contributed to the final manuscript.

\section{Acknowledgements}

We thank Aik Choon Tan and Troy Anderson for critical review of this manuscript. This work was supported by NHLBI NOI-HV-28I80 and ROIHL72488.

\section{References}

I. Liotta L, Petricoin E: Molecular Profiling Of Human Cancer. Nature Reviews Genetics 2000, I:48-56.

2. Bast RC Jr., Lilja H, Urban N, Rimm DL, Fritsche H, Gray J, Veltri R, Klee G, Allen A, Kim N, Gutman S, Rubin MA, Hruszkewycz A: 
Translational Crossroads for Biomarkers. Clin Cancer Res 2005, II(I7):6103-6I08.

3. Dhanasekaran SM, Barrette TR, Ghosh D, Shah R, Varambally S, Kurachi K, Pienta KJ, Rubin MA, Chinnaiyan AM: Delineation of prognostic biomarkers in prostate cancer. Nature 200I, 4| 2:822-826.

4. Chen X, Cheung ST, So S, Fan ST, Barry C, Higgins J, Lai KM, Ji J, Dudoit S, Ng IOL, van de Rijn M, Botstein D, Brown PO: Gene Expression Patterns in Human Liver Cancers. Mol Biol Cell 2002, 13(6): 1929-1939.

5. Su Al, Welsh JB, Sapinoso LM, Kern SG, Dimitrov P, Lapp H, Schultz PG, Powell SM, Moskaluk CA, Frierson HF Jr., Hampton GM: Molecular Classification of Human Carcinomas by Use of Gene Expression Signatures. Cancer Res 200I, 6 I (20):7388-7393.

6. Luo J, Duggan DJ, Chen Y, Sauvageot J, Ewing C, Bittner ML, Trent JM, Isaacs WB: Human prostate cancer and benign prostatic hyperplasia: molecular dissection by gene expression profiling. Cancer Research 200I, 6 I:4683-4688.

7. Yagi T, Morimoto A, Eguchi M, Hibi S, Sako M, Ishii E, Mizutani S, Imashuku $\mathrm{S}$, Ohki M, Ichikawa $\mathrm{H}$ : Identification of a gene expression signature associated with pediatric AML prognosis. Blood 2003, I 02(5): I849-1856.

8. lacobuzio-Donahue CA, Maitra A, Olsen M, Lowe AW, Van Heek NT, Rosty C, Walter K, Sato N, Parker A, Ashfaq R, Jaffee E, Ryu B, Jones J, Eshleman JR, Yeo CJ, Cameron JL, Kern SE, Hruban RH, Brown PO, Goggins M: Exploration of Global Gene Expression Patterns in Pancreatic Adenocarcinoma Using cDNA Microarrays. Am J Pathol 2003, 162(4): II5I-II62.

9. Watson MA, Gutmann DH, Peterson K, Chicoine MR, KleinschmidtDeMasters BK, Brown HG, Perry A: Molecular Characterization of Human Meningiomas by Gene Expression Profiling Using High-Density Oligonucleotide Microarrays. Am J Pathol 2002, $161(2): 665-672$.

10. Higgins JPT, Shinghal R, Gill H, Reese JH, Terris M, Cohen RJ, Fero M, Pollack JR, van de Rijn M, Brooks JD: Gene Expression Patterns in Renal Cell Carcinoma Assessed by Complementary DNA Microarray. Am J Pathol 2003, I 62(3):925-932.

II. Bittner M, Meltzer P, Chen Y, Jiang Y, Seftor E, Hendrix M, Radmacher M, Simon R, Yakhini Z, Ben-Dor A, Sampas N, Dougherty E, Wang E, Marincola F, Gooden C, Lueders J, Glatfelter A, Pollock P, Carpten J, Gillanders E, Leja D, Dietrich K, Beaudry C, Berens M, Alberts D, Sondak V, Hayward N, Trent J: Molecular classification of cutaneous malignant melanoma by gene expression profiling. Nature 2000, 406(6795):536-540

12. Golub TR, Slonim DK, Tamayo P, Huard C, Gaasenbeek M, Mesirov JP, Coller H, Loh ML, Downing JR, Caligiuri MA, Bloomfield CD, Lander ES: Molecular Classification of Cancer: Class Discovery and Class Prediction by Gene Expression Monitoring. Science 1999, 286(5439):53|-537.

13. Geman D, d'Avignon C, Naiman DQ, Winslow RL: Classifying gene expression profiles from pairwise mRNA comparison. Statistical Applications in Genetics and Molecular Biology 2004, 3(1): 19.

14. Xu L, Tan AC, Naiman DQ, Geman D, Winslow RL: Robust prostate cancer marker genes emerge from direct integration of inter-study microarray data. Bioinformatics 2005, 2I(20):3905-39II.

15. Tan AC, Naiman DQ, Xu L, Winslow RL, Geman D: Simple decision rules for classifying human cancers from gene expression profiles. Bioinformatics 2005, 2 I (20):3896-3904.

16. Yang X, Bentink S, Spang R: Detecting Common Gene Expression Patterns in Multiple Cancer Outcome Entities. Biomedical Microdevices 2005, 7(3):247-25I.

17. Rhodes DR, Yu J, Shanker K, Deshpande N, Varambally R, Ghosh D, Barrette T, Pandey A, Chinnaiyan AM: Large-scale meta-analysis of cancer microarray data identifies common transcriptional profiles of neoplastic transformation and progression. PNAS 2004, I0I(25):9309-93 I4.

18. Segal E, Friedman N, Koller D, Regev A: A module map showing conditional activity of expression modules in cancer. Nat Genet 2004, 36(10): 1090.

19. Price ND, Trent J, El-Naggar AK, Cogdell D, Taylor E, Hunt KK, Pollock RE, Hood L, Shmulevich I, Zhang W: Highly accurate twogene classifier for differentiating gastrointestinal stromal tumors and leiomyosarcomas. PNAS 2007, 104(9):34|4-34I9.

20. Barrett T, Troup DB, Wilhite SE, Ledoux P, Rudnev D, Evangelista C, Kim IF, Soboleva A, Tomashevsky M, Edgar R: NCBI GEO: mining tens of millions of expression profiles--database and tools update. Nucl Acids Res 2007, 35(suppl_I):D760-765.

21. Rhodes DR, Yu J, Shanker K, Deshpande N, Varambally R, Ghosh D, Barrette T, Pandey A, Chinnaiyan AM: ONCOMINE: A Cancer Microarray Database and Integrated Data-Mining Platform. Neoplasia 2004, 6: I

22. Basil CF, Zhao Y, Zavaglia K, Jin P, Panelli MC, Voiculescu S, Mandruzzato S, Lee HM, Seliger B, Freedman RS, Taylor PR, Hu N, Zanovello P, Marincola FM, Wang E: Common Cancer Biomarkers. Cancer Res 2006, 66(6):2953-2961.

23. Michiels S, Koscielny S, Hill C: Prediction of canceroutcome with microarrays: a multiple random validation strategy. Lancet 2005, 365(9458):488-492.

24. Pavlidis P, Noble WS: Matrix2png: a utility for visualizing matrix data. Bioinformatics 2003, 19(2):295-296.

25. Beer DG, Kardia SLR, Huang CC, Giordano TJ, Levin AM, Misek DE, Lin L, Chen G, Gharib TG, Thomas DG, Lizyness M, Kuick R, Hayasaka S, Taylor JMG, lannettoni MD, Orringer MB, Hanash SM: Geneexpression profiles predict survival of patients with lung adenocarcinoma. Nature Medicine 2002, 8(8):8|6-824.

26. Dyrskjot L, Thykjaer T, Kruhoffer M, Jensen JL, Marcussen N, Hamilton-Dutoit S, Wolf H, Orntoft TF: Identifying distinct classes of bladder carcinoma using microarrays. Nature Genetics 2003, 33:90-96.

27. Hippo Y, Taniguchi H, Tsutsumi S, Machida N, Chong JM, Fukayama M, Kodama T, Aburatani H: Global Gene Expression Analysis of Gastric Cancer by Oligonucleotide Microarrays. Cancer Res 2002, 62(I):233-240.

28. Hsiao LL, Dangond F, Yoshida T, Hong R, Jensen RV, Misra J, Dillon W, Lee KF, Clark KE, Haverty P, Weng Z, Mutter GL, Frosch MP, Macdonald ME, Milford EL, Crum CP, Bueno R, Pratt RE, Mahadevappa M, Warrington JA, Stephanopoulos G, Stephanopoulos G, Gullans SR: A compendium of gene expression in normal human tissues. Physiol Genomics 200I, 7(2):97-104.

29. Lancaster JM, Dressman HK, Whitaker RS, Havrilesky L, Gray J, Marks JR, Nevins JR, Berchuck A: Gene expression patterns that characterize advanced stage serous ovarian cancers. Journal of the Society for Gynecologic Investigation 2004, I I (I):5I-59.

30. Logsdon CD, Simeone DM, Binkley C, Arumugam T, Greenson JK, Giordano TJ, Misek DE, Hanash S: Molecular Profiling of Pancreatic Adenocarcinoma and Chronic Pancreatitis Identifies Multiple Genes Differentially Regulated in Pancreatic Cancer. Cancer Res 2003, 63(10):2649-2657.

31. Pomeroy SL, Tamayo P, Gaasenbeek M, Sturla LM, Angelo M, McLaughlin ME, Kim JYH, Goumnerova LC, Black PM, Lau C, Allen JC, Zagzag D, Olson JM, Curran T, Wetmore C, Biegel JA, Poggio T, Mukherjee S, Rifkin R, Califano A, Stolovitzky G, Louis DN, Mesirov JP, Lander ES, Golub TR: Prediction of central nervous system embryonal tumour outcome based on gene expression. Nature 2002, 41 5:436-442.

32. Quade BJ, Mutter GL, Morton CC: Comparision of Gene expression in Uterine Smooth Muscle Tumors. Gene Expression Omnibus: GSE764; 2003.

33. Ramaswamy S, Tamayo P, Rifkin R, Mukherjee S, Yeang $\mathrm{CH}$, Angelo M, Ladd C, Reich M, Latulippe E, Mesirov JP, Poggio T, Gerald W, Loda M, Lander ES, Golub TR: Multiclass cancer diagnosis using tumor gene expression signatures. PNAS 2001, 98(26): $15 \mid 49-15154$.

34. Rickman DS, Bobek MP, Misek DE, Kuick R, Blaivas M, Kurnit DM, Taylor J, Hanash SM: Distinctive Molecular Profiles of HighGrade and Low-Grade Gliomas Based on Oligonucleotide Microarray Analysis. Cancer Res 200I, 6I( I8):6885-689I.

35. Welsh JB, Zarrinkar PP, Sapinoso LM, Kern SG, Behling CA, Monk BJ, Lockhart DJ, Burger RA, Hampton GM: Analysis of gene expression profiles in normal and neoplastic ovarian tissue samples identifies candidate molecular markers of epithelial ovarian cancer. PNAS 200I, 98(3): II76-II8I.

36. Zhan F, Hardin J, Kordsmeier B, Bumm K, Zheng M, Tian E, Sanderson $R$, Yang $Y$, Wilson C, Zangari M, Anaissie E, Morris C, Muwalla F, van Rhee F, Fassas A, Crowley J, Tricot G, Barlogie B, Shaughnessy J Jr.: Global gene expression profiling of multiple myeloma, monoclonal gammopathy of undetermined significance, and normal bone marrow plasma cells. Blood 2002, 99(5): 1745-1757.

37. Bhattacharjee A, Richards WG, Staunton J, Li C, Monti S, Vasa P, Ladd C, Beheshti J, Bueno R, Gillette M, Loda M, Weber G, Mark EJ, Lander ES, Wong W, Johnson BE, Golub TR, Sugarbaker DJ, Meyerson M: 
Classification of human lung carcinomas by mRNA expression profiling reveals distinct adenocarcinoma subclasses. PNAS 200I, 98(24): I3790-I3795.

38. Cromer A, Carles A, Millon R, Ganguli G, Chalmel F, Lemaire F, Young J, Dembele D, Thibault C, Muller D, Poch O, Abecassis J, AWasylyk B: Idenfification of genes associated with tumorigenesis and metastatic potential of hypopharyngeal cancer by microarray analysis. Oncogene 2003, 23( I4):2484-2498.

39. Dehan E, Kaminski N: Non Small Cell Lung Cancer. Gene Expression Onmibus: GSEI 987; 2004.

40. Frierson HF Jr., El-Naggar AK, Welsh JB, Sapinoso LM, Su AI, Cheng J, Saku T, Moskaluk CA, Hampton GM: Large Scale Molecular Analysis Identifies Genes with Altered Expression in Salivary Adenoid Cystic Carcinoma. Am J Pathol 2002, I 6 I (4): I 3 I5-I 323.

4I. Giordano T], Thomas DG, Kuick R, Lizyness M, Misek DE, Smith AL, Sanders D, Aljundi RT, Gauger PG, Thompson NW, Taylor JMG, Hanash SM: Distinct Transcriptional Profiles of Adrenocortical Tumors Uncovered by DNA Microarray Analysis. Am J Pathol 2003, I62(2):52I-53I.

42. Gutmann DH, Hedrick NM, Li J, Nagarajan R, Perry A, Watson MA Comparative Gene Expression Profile Analysis of Neurofibromatosis I-associated and Sporadic Pilocytic Astrocytomas. Cancer Res 2002, 62(7):2085-209I.

43. Huang Y, Prasad M, Lemon WJ, Hampel H, Wright FA, Kornacker K, LiVolsi V, Frankel W, Kloos RT, Eng C, Pellegata NS, de la Chapelle A: Gene expression in papillary thyroid carcinoma reveals highly consistent profiles. PNAS 200I, 98(26): I 5044-I5049.

44. Shai R, Shi T, Kremen TJ, Horvath S, Liau LM, Cloughesy TF, Mischel PS, Nelson SF: Gene expression profiling identifies molecular subtypes of gliomas. Oncogene 2003, 22(3 I):4918-4923.

45. Stearman RS, Dwyer-Nield L, Zerbe L, Blaine SA, Chan Z, Bunn PA Jr., Johnson GL, Hirsch FR, Merrick DT, Franklin WA, Baron AE, Keith RL, Nemenoff RA, Malkinson AM, Geraci MW: Analysis of Orthologous Gene Expression between Human Pulmonary Adenocarcinoma and a Carcinogen-Induced Murine Model. Am J Pathol 2005, I67(6): I763-1775.

46. Su Al, Cooke MP, Ching KA, Hakak Y, Walker JR, Wiltshire T, Orth AP, Vega RG, Sapinoso LM, Mogrich A, Patapoutian A, Hampton GM, Schultz PG, Hogenesch JB: Large-scale analysis of the human and mouse transcriptomes. PNAS 2002, 99(7):4465-4470.

47. Welle S, Brooks A, Thornton C: Computational method for reducing variance with Affymetrix microarrays. BMC Bioinformatics 2002, 3(I):23.

48. Yanai I, Benjamin H, Shmoish M, Chalifa-Caspi V, Shklar M, Ophir R, Bar-Even A, Horn-Saban S, Safran M, Domany E, Lancet D, Shmueli O: Genome-wide midrange transcription profiles reveal expression level relationships in human tissue specification. Bioinformatics 2005, 2 I (5):650-659.

49. Yu YP, Landsittel D, Jing L, Nelson J, Ren B, Liu L, McDonald C, Thomas R, Dhir R, Finkelstein S, Michalopoulos G, Becich M, Luo JH: Gene Expression Alterations in Prostate Cancer Predicting Tumor Aggression and Preceding Development of Malignancy. J Clin Oncol 2004, 22( 1 4):2790-2799.

50. Gordon G]: Malignant pleural mesothelioma. Gene Expression Omnibus: GSE2549; 2005.

51. Hoffman PJ, Milliken DB, Davis RP, Gregg JP: Uterine Fibroid and Normal Myometrial Expression Profiles. Gene Expression Omnibus: GSE593; 2003.

52. Lenburg M, Liou L, Gerry N, Frampton G, Cohen H, Christman M Previously unidentified changes in renal cell carcinoma gene expression identified by parametric analysis of microarray data. BMC Cancer 2003, 3(I):3I.

53. Talantov D, Mazumder A, Yu JX, Briggs T, Jiang Y, Backus J, Atkins D, Wang Y: Novel Genes Associated with Malignant Melanoma but not Benign Melanocytic Lesions. Clin Cancer Res \% R I 1 I 58 / I078-0432CCR-05-0683 2005, I I(20):7234-7242.

54. Wachi S, Yoneda K, Wu R: Squamous Lung Cancer. Gene Expression Omnibus: GSE3268; 2005.

55. Yoon SS, Segal NH, W. RS, Detwiller KY, D'Amore PA, Fernando NT: Gene expression of human soft tissue sarcoma. Gene Expression Onmibus: GSE2719; 2005.

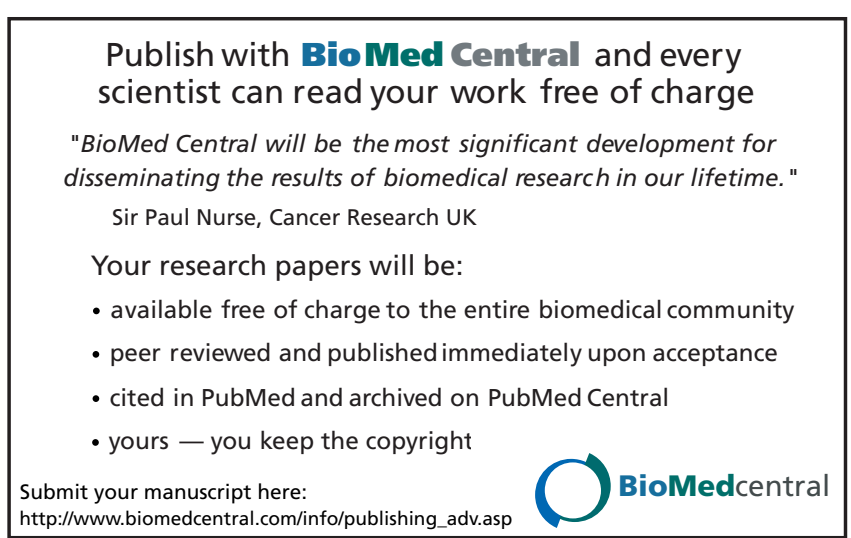

